IRRITABLE BOWEL SYNDROME

\title{
Diagnostic yield of alarm features in irritable bowel syndrome and functional dyspepsia
}

\author{
J Hammer, G D Eslick, S C Howell, E Altiparmak, N J Talley
}

Gut 2004;53:666-672. doi: 10.1136/gut.2003.021857

Objective: The diagnostic value of the addition of alarm symptoms in distinguishing functional from organic gastrointestinal disease remains uncertain. We aimed to establish the value of alarm features in differentiating between organic disease and irritable bowel syndrome (IBS) and functional dyspepsia (FD). Methods: A total of 568 consecutive patients (63\% female; mean age 44.7 years) completed a detailed symptom questionnaire and then received a complete diagnostic workup, as required. Questionnaire data were collected prospectively and audited retrospectively; the treating physician was blinded to the results of the questionnaires. Patients were coded and allocated to the following diagnostic groups: IBS, FD, organic diseases of the upper gastrointestinal tract, or organic diseases of the lower gastrointestinal tract. Logistic regression was used to identify the best subset of symptoms that discriminated organic disease from functional illness. Separate models compared IBS $(n=214)$ with diseases of the lower gastrointestinal tract $(n=66)$, and FD $(n=70)$ with diseases of the upper gastrointestinal tract $(n=250)$.

Results: Age (50 years at symptom onset: odds ratio (OR) 2.65 (95\% confidence interval 1.4-5.0); $p=0.002)$ and blood on the toilet paper (OR $2.7(1.4-5.1) ; p=0.002)$ emerged as alarm features that discriminated IBS from lower gastrointestinal illness. A diagnosis of IBS was typically associated with

See end of article for authors' affiliations

Correspondence to

Dr J Hammer,

Universitätsklinik für Innere

Medizin IV, Währinger

Gürtel 18-20, 1090

Vienna, Austria; Johann.

Hammer@univie.ac.at

Accepted for publication 15 October 2003 female sex (OR2.5 (1.3-4.6); $p=0.004)$, pain on six or more occasions in the previous year (OR 5.0 $(2.2-11.1) ; p<0.001)$, pain that radiated outside of the abdomen (OR $2.9(1.4-6.3) ; p=0.006)$, and pain associated with looser bowel motions (OR $2.1(1.1-4.2) ; p=0.03)$. A model incorporating three Manning criteria and alarm features yielded a correct diagnosis of IBS in $96 \%$ and a correct diagnosis of organic disease in 52\% of cases. Alarm features did not discriminate FD from upper gastrointestinal disease. Patients with FD were significantly more likely to report upper abdominal pain (OR 3.7 (1.7-8.3); $p=0.002)$ and significantly less likely to report aspirin use (OR $0.26(0.1-0.6) ; p=0.001)$. The predictive value of symptoms in diagnosing FD was only $17 \%$.

Conclusions: Symptoms plus alarm features have a high predictive value for diagnosing IBS but the predictive value for a diagnosis of FD remains poor. Current criteria for the diagnosis of IBS should incorporate relevant alarm features to improve the diagnostic yield.
F unctional gastrointestinal disorders such as the irritable bowel syndrome (IBS) or functional dyspepsia (FD) are the most common disorders encountered by the gastroenterologist and constitute a considerable economic burden to the health care system. ${ }^{1-3}$ However, the accuracy of a diagnosis based purely on the presenting gastrointestinal symptoms continues to worry practising physicians. ${ }^{4}$ Traditionally, a diagnosis of a functional bowel disorder is based on the classical symptom patterns in the absence of an organic explanation by appropriate testing. Thus IBS is diagnosed when unexplained abdominal pain and bowel symptoms coexist ${ }^{5}$ while FD is identified when unexplained upper abdominal pain or discomfort is present in those with normal upper endoscopy. ${ }^{6}$ The role of other potential diagnostic criteria remains unclear. ${ }^{7}$

There is a limit to the repertoire of gastrointestinal symptoms and hence it is understandable that symptoms alone may not be accurate enough to identify functional from organic disease. However, in the absence of a reproducible and accepted biological marker, symptoms currently remain the primary means of identifying patients in clinical practice and recruiting patients for research studies. Several diagnostic approaches that are based on the patient's symptoms, such as the Manning criteria, ${ }^{8}$ the Kruis scoring system, ${ }^{9}$ or the Rome criteria, ${ }^{510}$ have been proposed to assist the diagnostic process. However, the available literature suggests that symptom based diagnostic algorithms, although often used for clinical and research studies, have poor sensitivity. ${ }^{11-16}$ Although diagnostic algorithms such as the Manning criteria or the Rome criteria can discriminate IBS from health or upper gastrointestinal tract conditions, studies do not provide convincing evidence that the criteria can discriminate IBS from organic disease of the colon. ${ }^{6}{ }^{17}$ Moreover, symptom patterns appear to be unable to adequately discriminate organic from FD. ${ }^{18}$ Thus in clinical practice functional gastrointestinal disorders are still often identified by exclusion. ${ }^{19}$

In daily clinical practice, history taking includes a search for leading symptoms, as suggested by diagnostic algorithms for functional bowel disorders, as well as an intensive clinical search for evidence of organic disease (alarm symptoms or features), such as older age at symptom onset, weight loss, gastrointestinal bleeding, dysphagia, and vomiting. Current guidelines recommend a full diagnostic workup in patients who present with such alarm features. ${ }^{10}$ Vanner and colleagues $^{20}$ suggested that evaluating alarm symptoms in combination with the Rome I criteria improved the predictive value for diagnosing IBS. However, the value of these symptoms in discriminating organic disease from functional disorders remains uncertain, especially as alarm features are common, even in younger people in the general population. ${ }^{21}$

Abbreviations: IBS, irritable bowel syndrome; FD, functional dyspepsia; OR, odds ratio 
We hypothesised that a history taking process evaluating both the presence of alarm features and symptom based algorithms might have the potential to increase diagnostic yield and avoid unnecessary diagnostic studies in functional gastrointestinal disorders. Such information would support changing the Rome diagnostic criteria accordingly. In the present study therefore, our aim was to assess the value of alarm features in differentiating organic disease from IBS and FD.

\section{METHODS}

\section{Patient sample}

All patients who attended a specialist gastroenterology practice (NJT) at the Nepean Hospital in Western Sydney between June 1994 and December 1998 were included in the study. Patients were primarily referred by general practitioners but also by surgeons and other internists. At their first visit, all patients were asked to complete the previously validated bowel symptom questionnaire ${ }^{22}$ and were offered a full diagnostic workup, as considered appropriate based on the presenting symptoms. Questionnaire data were collected prospectively in the above mentioned time period. Data were then retrospectively audited.

All functional disorders were diagnosed based on the history, physical examination, and appropriate negative diagnostic tests, including upper and/or lower endoscopy. Before establishing a final diagnosis, physicians were blinded concerning the results of the questionnaire; thus data collected by the questionnaires were not used clinically. The final diagnosis was reviewed by at least one other gastroenterologist and, in cases where there were divergent opinions about the diagnosis, patients histories were reviewed together to arrive at an agreed diagnosis. Patients were excluded if they had not received a full diagnostic workup or had not received a diagnosis of organic gastrointestinal disease, IBS, or FD. Alarm features, gastrointestinal symptoms, and possible risk factors (non-alarm featuresthat is, pain based symptoms, bowel symptoms, other abdominal risk indicators, and non-gastrointestinal risk factors) were considered for analysis; these are summarised in tables 1 and 2 , respectively.

\section{Statistical analyses}

Prevalence estimates are reported for all symptoms and for all disease risk factors, stratified by diagnostic group membership; univariate associations were assessed using Pearson's $\chi^{2}$ test. Two sets of a priori comparisons were performed-IBS versus organic illnesses of the lower gastrointestinal tract, and FD versus organic illness of the upper gastrointestinal tract.

Logistic regression was used to assess the value of alarm features in discriminating functional disorders from organic disease. Separate models were developed for lower gastrointestinal illness (versus IBS) and for upper gastrointestinal illness (versus FD). Alarm features were entered into a regression model, and backward stepwise elimination was used to identify the best subset of symptoms that predicted a diagnosis of organic disease. The best subset of non-alarm feature items (that is, pain based symptoms, bowel symptoms, other abdominal risk indicators, and non-gastrointestinal risk factors) was then identified using an identical approach. Unadjusted and adjusted odds ratios for alarm features are reported.

The logistic regression model was based on symptoms. Symptom families were created and consisted of three groups: (i) alarm features; (ii) non-alarm features; and (iii) other symptoms. Identified within each family was the best subset of predictors using backward stepwise logistic regression. The three best subgroups identified underwent a further backward elimination to identify any significant effects. We recognised that using this regression procedure there was an increased probability of a type I error, and thus we elected to set a more stringent cutoff $(p=0.05)$ for inclusion in the model as a method of controlling for any potential type I error.

There was no sample size calculations performed for this study initially as it was based on an opportunistic sample of patients in a gastroenterology practice. However, a retrospective power calculation was performed, based on the sample required to assess effects at a 5\% alpha level with $80 \%$ statistical power: effect sizes were estimated to reflect both protective and risk factors assuming a range of prevalences (table 2). Based on the available sample for this study, an effect size (odds ratios) in the range $0.11-0.39$ was detected for protective factors, assuming no correlation between predictive items; this ranged from 0.00 to 0.22 when a high correlation was assumed between items (that is, $r=0.5$ ). Corresponding ranges for risk factors were 2.12-3.15 (uncorrelated) and 2.80-4.82 (correlated). Hence the study was sufficiently powered.

Table 1 Prevalence estimates for gastrointestinal (GI) diagnosis according to $\mathrm{Gl}$ alarm symptoms

\begin{tabular}{|c|c|c|c|c|}
\hline & \multicolumn{2}{|c|}{ Lower GI disease $v$ IBS } & \multicolumn{2}{|c|}{ Upper GI disease v FD } \\
\hline & $\begin{array}{l}\text { Lower } \mathrm{GI} \text { organic } \\
\text { disease }(\mathrm{n}=66)(\%)\end{array}$ & $\begin{array}{l}\text { IBS } \\
(n=214)(\%)\end{array}$ & $\begin{array}{l}\text { Upper GI organic } \\
\text { disease }(n=251) \\
(\%)\end{array}$ & $\begin{array}{l}\mathrm{FD}(n=70) \\
(\%)\end{array}$ \\
\hline Age $>45 y$ & 56.1 & $37.9^{\star *}$ & 57.8 & 47.1 \\
\hline Age $>50 y$ & 45.5 & $23.4^{\star \star *}$ & 45.8 & 34.3 \\
\hline Age $>55 y$ & 36.4 & $14.5^{\star \star *}$ & 32.7 & 22.9 \\
\hline Female sex & 51.5 & $78.0^{* * *}$ & 52.6 & 62.9 \\
\hline Nocturnal pain & 43.9 & 56.1 & 43.0 & 52.9 \\
\hline Blood coating stools & 19.7 & $7.0^{*}$ & 4.8 & 4.3 \\
\hline Blood mixed with stools & 19.7 & $7.9^{* *}$ & 3.6 & 2.9 \\
\hline Blood on the toilet paper & 42.4 & $21.0^{* * *}$ & 13.9 & 11.4 \\
\hline Recurrent vomiting & 13.6 & 12.1 & 9.6 & 8.6 \\
\hline Severe pain & 33.3 & $54.2^{* \star}$ & 33.9 & 40.0 \\
\hline Weekly pain & 59.1 & $74.8^{* *}$ & 52.6 & 61.4 \\
\hline Altered bowel habit & 48.5 & 53.3 & 27.5 & 25.7 \\
\hline Dysphagia & 13.6 & $26.6^{*}$ & 23.1 & 28.6 \\
\hline Weight loss $<7 \mathrm{lb}$ & 16.1 & 14.8 & 8.5 & 14.3 \\
\hline Weight loss $>7 \mathrm{lb}$ & 16.1 & 15.2 & 8.1 & 14.3 \\
\hline Decreased appetite & 19.7 & 25.2 & 16.3 & $28.6^{*}$ \\
\hline
\end{tabular}

IBS, irritable bowel syndrome; FD, functional dyspepsia. ${ }^{*} p<0.05 ;{ }^{* *} p<0.01 ;{ }^{* * *} p<0.001$. 


\begin{tabular}{|c|c|c|c|c|}
\hline & \multicolumn{2}{|c|}{ Lower GI illness $v$ IBS } & \multicolumn{2}{|c|}{ Upper GI illness v FD } \\
\hline & $\begin{array}{l}\text { Lower GI illness } \\
\text { (\%) }\end{array}$ & $\begin{array}{l}\text { IBS } \\
\text { (\%) }\end{array}$ & $\begin{array}{l}\text { Upper GI illness } \\
\text { (\%) }\end{array}$ & $\begin{array}{l}\text { FD } \\
\text { (\%) }\end{array}$ \\
\hline \multicolumn{5}{|l|}{ Abdominal pain } \\
\hline Upper abdominal pain & 37.9 & $62.6^{* * *}$ & 66.1 & $88.6^{* * *}$ \\
\hline Lower abdominal pain & 66.7 & $79.9^{*}$ & 33.5 & 31.4 \\
\hline Pain history $>2 y$ & 36.4 & $56.5^{\star *}$ & 39.4 & 37.1 \\
\hline Pain $>6$ times $/$ year & 66.7 & $93.9^{* * *}$ & 64.5 & $82.9^{* *}$ \\
\hline Intermittent pain & 40.9 & 46.7 & 42.6 & 48.6 \\
\hline Pain lasting $>30 \mathrm{~min}$ & 48.5 & $76.6^{* * *}$ & 54.2 & 67.1 \\
\hline Pain before meals & 10.6 & 17.8 & 22.3 & 30.0 \\
\hline Pain $<30$ min after meals & 18.2 & 28.5 & 24.7 & 28.6 \\
\hline Pain $>30$ min after meals & 37.9 & 42.1 & 38.6 & 41.4 \\
\hline Radiating outside belly & 15.2 & $43.0^{* * *}$ & 27.5 & $40.0^{*}$ \\
\hline \multicolumn{5}{|l|}{ Pain relieved by } \\
\hline Belching & 13.6 & 18.2 & 26.7 & 31.4 \\
\hline Bowel movement & 33.3 & $55.1^{* *}$ & 26.7 & 24.3 \\
\hline Eating & 7.6 & $19.2^{*}$ & 17.9 & 15.7 \\
\hline Antacids & 9.1 & 15.4 & 31.5 & 24.3 \\
\hline \multicolumn{5}{|l|}{ Pain made worse by } \\
\hline Food or milk & 28.8 & 40.2 & 28.7 & 40.0 \\
\hline Alcohol & 7.6 & 15.4 & 22.7 & 20.0 \\
\hline \multicolumn{5}{|l|}{ Pain associated with: } \\
\hline More bowel movements & 37.9 & 50.9 & 22.3 & 21.4 \\
\hline Looser bowel movements & 30.3 & $50.0^{* *}$ & 24.3 & 24.3 \\
\hline \multicolumn{5}{|l|}{ Bowel symptoms } \\
\hline Mucus per rectum & 34.8 & 35.5 & 15.1 & 15.7 \\
\hline$<3$ movements weekly & 12.1 & 12.6 & 8.4 & 12.9 \\
\hline$>3$ movements daily & 34.8 & 30.8 & 17.1 & 12.9 \\
\hline Straining on defecation & 40.9 & 46.7 & 35.1 & 30.0 \\
\hline Loose/watery stools & 51.5 & 54.7 & 29.9 & 27.1 \\
\hline Hard/lumpy stools & 34.8 & 41.6 & 33.1 & 40.0 \\
\hline Incomplete evacuation & 57.6 & $72.4^{*}$ & 48.2 & 41.4 \\
\hline Urgency & 50.0 & 62.1 & 38.6 & 28.6 \\
\hline Constipation & 3.0 & 5.6 & 3.2 & $10.0^{*}$ \\
\hline Diarrhoea & 18.2 & $8.9^{*}$ & 5.6 & 5.7 \\
\hline \multicolumn{5}{|l|}{ Other GI risk factors } \\
\hline Nausea & 22.7 & $39.3^{* *}$ & 31.5 & 40.0 \\
\hline Heartburn & 24.2 & 30.4 & 55.0 & $41.4^{*}$ \\
\hline Reflux & 9.1 & $23.8^{* *}$ & 39.0 & 27.1 \\
\hline Bloating & 53.0 & $75.2^{* \star *}$ & 55.8 & 52.9 \\
\hline Abdominal surgery & 48.5 & 61.7 & 57.4 & 54.3 \\
\hline Ulcer & 22.7 & 17.3 & 29.5 & 25.7 \\
\hline Childhood history & 12.1 & $26.6^{* *}$ & 15.1 & 18.6 \\
\hline \multicolumn{5}{|l|}{ Other risk factors } \\
\hline Current smoker & 19.7 & 24.8 & 17.5 & 22.9 \\
\hline Alcohol use (any) & 69.7 & $53.7^{* *}$ & 59.8 & 58.6 \\
\hline Aspirin use (any) & 27.3 & 19.6 & 33.1 & $11.4^{* \star *}$ \\
\hline Paracetamol use & 9.1 & $19.6^{*}$ & 66.1 & $78.6^{*}$ \\
\hline
\end{tabular}

An alpha level of 5\% was applied in the univariate analyses, and was set as the cutoff for elimination during both stages of the modelling process. Regression analysis included as candidates all items that were significant in the univariate tests.

\section{RESULTS}

\section{Patients}

In total, 806 consecutive patients entered the study. Two hundred and thirty eight patients were excluded in accordance with the following criteria: $\mathrm{n}=89$ had functional illnesses that did not meet the Rome II criteria for IBS or dyspepsia; $\mathrm{n}=103$ had not been given a final diagnosis and as patients did not undergo all diagnostic procedures that were considered necessary, a common diagnosis could not be arrived at $(\mathrm{n}=4) ; \mathrm{n}=39$ had non-gastrointestinal disorders; and $n=7$ were diagnosed as normal. A further 92 subjects were excluded due to missing data. The final sample consisted of 568 patients; 212 were male $(37.3 \%)$ and 356 were female $(62.7 \%)$. Mean patient age was 48.1 years (SD
16.01). Males were significantly older than females (49.6 (16.2) $v 47.3$ (15.9) years; $\mathrm{p}=0.03$ ).

The distribution of lower gastrointestinal organic diagnoses were inflammatory bowel disease $(n=23)$, other types of colitis $(n=9)$, diverticular disease $(n=9)$, colon cancer or polyps $(\mathrm{n}=11)$, anal disease $(\mathrm{n}=5)$, faecal incontinence $(\mathrm{n}=2)$, intestinal pseudo-obstruction $(\mathrm{n}=2)$, drug related diarrhoea $(n=3)$, connective tissues disease $(n=1)$, and lactose intolerance $(n=1)$. Upper gastrointestinal organic diseases were peptic ulcer ( $\mathrm{n}=29$ ), gastro-oesophageal reflux diseases $(n=148)$, other oesophageal diseases $(n=8)$, other gastric diseases including motility disorders $(n=14)$, coeliac disease $(n=9)$, liver or gall bladder disease $(n=33)$, pancreatic disease $(\mathrm{n}=2)$, and postoperative syndromes $(n=7)$. Overlapping diagnoses were reported in 40 cases. These involved a diagnosis of organic disease (upper and/or lower) in conjunction with IBS, dyspepsia, or both. Patients with overlapping diagnosis were coded as organic gastrointestinal disease in preference to functional illness, as appropriate. For example, three patients had a diagnosis of 
upper gastrointestinal disease in conjunction with IBS and dyspepsia: these were coded as organic disease in the comparison between upper gastrointestinal disease and dyspepsia, but as functional disease in the comparison between lower gastrointestinal disease and IBS.

\section{Lower organic gastrointestinal disease versus IBS}

In total, $\mathrm{n}=280$ patients were available for the comparison of lower gastrointestinal organic disease versus IBS. Mean age of these patients was 42.0 years (SD 15.7), and $71.8 \%$ $(\mathrm{n}=201)$ were female.

\section{Alarm features}

Ten of 16 alarm features discriminated lower gastrointestinal organic disease from IBS in univariate tests (table 1). Patients with organic disease (lower gastrointestinal tract) were significantly more likely to achieve the age cutoffs of 45 years $(56.1 \% \quad v \quad 37.9 \%$; $p=0.009), \quad 50$ years $(45.5 \% \quad v \quad 23.4 \%$; $\mathrm{p}=0.001)$, and 55 years $(36.4 \% \vee 14.5 \% ; \mathrm{p}=0.001)$, and were more likely to report symptoms of rectal bleeding (blood coating stools $19.7 \% \vee 7.0 \%(p=0.03)$; blood mixed with stools $19.7 \% v 7.9 \%(\mathrm{p}=0.007)$; blood on toilet paper $42.4 \% v$ $21.0 \%(\mathrm{p}=0.001))$. In contrast, patients with IBS were significantly more likely to be female $(78.0 \% \quad v 51.5 \%$; $\mathrm{p}=0.001)$, to report severe pain $(54.2 \% v 33.3 \% ; \mathrm{p}=0.003)$ or frequent (at least weekly) pain $(74.8 \% \vee 59.1 \%$; $\mathrm{p}=0.01)$, and to report symptoms of dysphagia (26.6\% $v 13.6 \%$; $\mathrm{p}=0.03)$.

Logistic regression identified four alarm features that were significantly and independently related to a diagnosis of lower gastrointestinal organic disease (see table 3; unadjusted models). The odds of organic disease were increased among those aged more than 50 years (odds ratio (OR) 2.65 (95\% confidence interval (CI) 1.41-4.97); $\mathrm{p}=0.002$ ) (the age cutoffs of 45 and 55 years were not considered in the modelling procedure) and among those who reported blood on their toilet paper (OR 2.70 (95\% CI 1.42-5.13); $\mathrm{p}=0.002$ ). In contrast, the odds of organic disease were reduced among females (OR 0.40 (95\% CI 0.22-0.75); $\mathrm{p}=0.004$ ) and among patients who reported severe pain (OR 0.46 (95\% CI $0.25-$ $0.85) ; \mathrm{p}=0.014)$.

\section{Non-alarm features}

Other symptoms that are generally not considered alarm symptoms were also assessed for their value in discriminating lower gastrointestinal organic disease from IBS (table 2). Abdominal pain and some of its associated features also discriminated lower gastrointestinal disease from IBS in univariate tests. Both upper and lower abdominal pain were typically more common in patients with IBS (upper abdominal pain $62.6 \%$ v 37.9\% $(\mathrm{p}<0.001)$; lower abdominal pain $79.9 \% \vee 66.7 \%(\mathrm{p}=0.03))$, as was pain that radiated outside of the abdomen (43.0\% v 15.2\%; $<<0.001)$. Patients with IBS were also more likely to report a duration of abdominal pain of greater than two years (56.5\% $v 36.4 \%$; $\mathrm{p}=0.004)$, pain on six or more occasions in the past year (93.9\% v 66.7\%; $\mathrm{p}<0.001)$, and pain episodes lasting more than 30 minutes in duration (76.6\% v 48.5\%; $\mathrm{p} \leqslant 0.001)$. Pain relieved by bowel movements and by eating was more common among patients with IBS (bowel movements $55.1 \%$ $v 33.3 \%(\mathrm{p}=0.002)$; eating $19.2 \% v 7.6 \%(\mathrm{p}=0.03))$, as was pain associated with looser stools $(50.0 \%$ v 30.3\%; $\mathrm{p}=0.005)$.

Two of eight bowel symptoms discriminated lower gastrointestinal disease from a diagnosis of IBS. Incomplete evacuation was more common among patients with IBS $(72.4 \%$ v 57.6\%; $\mathrm{p}=0.02)$, and diarrhoea was more common among patients with lower gastrointestinal disease $(18.2 \% v$ $8.9 \% ; \mathrm{p}=0.04)$. Similarly, patients with the IBS were more likely than those with lower gastrointestinal disease to report other gastrointestinal symptoms, including nausea $(39.3 \% v$ $22.7 \% ; \mathrm{p}=0.01)$, acid regurgitation $(23.8 \%$ v $9.1 \%$; $\mathrm{p}=0.009)$, and bloating $(75.2 \% \vee 53.0 \% ; \mathrm{p}=0.001)$.

Patients with IBS were more likely to report a childhood history of abdominal pain $(26.6 \% \vee 12.1 \% ; \mathrm{p}=0.02)$ and regular paracetamol (acetaminophen) use (19.6\% v 9.1\%). In contrast, patients with lower gastrointestinal disease were more likely to report any alcohol use $(69.7 \%$ v 53.7\%; $\mathrm{p}=0.02$ ).

Logistic regression identified five non-alarm feature items that were significantly related to a diagnosis of lower gastrointestinal disease (see table 3: unadjusted models). The odds of a diagnosis of organic disease were significantly lower among patients who reported pain on more than six occasions in the previous year (OR 0.20 (95\% CI 0.09-0.46); $\mathrm{p}<0.001$ ), radiating pain (OR 0.34 (95\% CI $0.16-0.73$ ); $\mathrm{p}=0.006)$, pain associated with looser bowel movements (OR 0.48 (95\% CI 0.24-0.94); $\mathrm{p}<0.03$ ), and acid reflux (OR 0.32 (95\% CI 0.12-0.83); $\mathrm{p}=0.02$ ). The odds of a diagnosis of organic disease were higher among patients who reported diarrhoea (OR 3.49 (95\% CI 1.40-8.67); p <0.001).

\section{Alarm features: adjusted model}

Table 3 shows the effects of alarm features on a diagnosis of lower gastrointestinal disease following adjustment for significant (non-alarm) predictors (see adjusted models). Three of four alarm features from the unadjusted model remained significant after adjustment for the effects of nonalarm items: these included the age cutoff of 50 years (OR 2.96 (95\% CI 1.47-5.94); $\mathrm{p}<0.002$ ), female sex (OR $0.43(95 \%$ CI $0.22-0.86) ; \mathrm{p}<0.02$ ), and blood on the toilet paper (OR

Table 3 Multivariate relationships between alarm symptoms and lower gastrointestinal diagnostic groups: unadjusted and adjusted effects

\begin{tabular}{|c|c|c|c|c|c|c|}
\hline & \multicolumn{3}{|c|}{ Unadjusted model } & \multicolumn{3}{|c|}{ Adjusted model* } \\
\hline & $\overline{O R}$ & $95 \% \mathrm{Cl}$ & $p$ Value & $\overline{O R}$ & $95 \% \mathrm{Cl}$ & p Value \\
\hline \multicolumn{7}{|l|}{ Alarm features } \\
\hline Age $>50 y$ & 2.65 & $1.41-4.97$ & 0.002 & 2.96 & $1.47-5.94$ & 0.002 \\
\hline Female sex & 0.40 & $0.22-0.75$ & 0.004 & 0.43 & $0.22-0.86$ & 0.017 \\
\hline Blood on toilet paper & 2.70 & $1.42-5.13$ & 0.002 & 2.19 & $1.06-4.52$ & 0.034 \\
\hline Severe pain & 0.46 & $0.25-0.85$ & 0.014 & 0.85 & $0.42-1.74$ & 0.662 \\
\hline \multicolumn{7}{|l|}{ Other symptoms and risk factors } \\
\hline Pain $>6$ times in the past year & 0.20 & $0.09-0.46$ & $<0.001$ & 0.21 & $0.08-0.52$ & 0.001 \\
\hline Radiating pain & 0.34 & $0.16-0.73$ & 0.006 & 0.38 & $0.16-0.88$ & 0.024 \\
\hline Pain/looser bowel movements & 0.48 & $0.24-0.94$ & 0.032 & 0.47 & $0.23-0.96$ & 0.037 \\
\hline Diarrhoea & 3.49 & $1.40-8.67$ & 0.007 & 2.69 & $1.03-7.02$ & 0.043 \\
\hline Reflux & 0.32 & $0.12-0.83$ & 0.019 & 0.36 & $0.13-0.98$ & 0.046 \\
\hline
\end{tabular}

*Adjustments were performed for significant alarm features and non-alarm features, respectively.

$\mathrm{OR}$, odds ratio; $95 \% \mathrm{Cl}, 95 \%$ confidence interval. 
2.19 (95\% CI 1.06-4.52); $<<0.03$ ). Severe pain was no longer significant after adjustment for non-alarm items (OR 0.85 (95\% CI 0.42-1.74); $\mathrm{p}>0.05$ ).

Table 4 shows the classification statistics for the various models of lower organic disease versus IBS. These allow the predictive value of the alarm features and non-alarm items to be assessed. The predicted values reflect the diagnosis expected on the basis of the model while the observed values reflect the actual diagnosis given.

The model containing alarm features alone (model 1) correctly classified $92.5 \%$ of patients with IBS and $31.8 \%$ of patients with lower gastrointestinal disease. This was improved in the model containing only non-alarm feature items (model 2), with correct classification occurring in $95.3 \%$ of cases with IBS and $36.4 \%$ of cases with organic disease. However, the best discrimination was provided by the model that contained both alarm features and non-alarm feature items, with correct classification occurring in $95.8 \%$ of cases with IBS and $51.5 \%$ of cases with organic disease. Inclusion of the Manning criteria improved the classification statistics slightly, but only when the cutoff was set at three or four of the six Manning symptoms.

\section{Upper organic gastrointestinal disease versus FD}

In total, $\mathrm{n}=321$ patients were available for the comparison of organic diseases of the upper gastrointestinal tract with FD. Mean age of these patients was 47.7 years (SD 15.0); $54.8 \%$ $(n=176)$ were female.

\section{Alarm features}

Only one of sixteen alarm features discriminated upper gastrointestinal disease from FD (table 1). Patients with organic upper gastrointestinal disease were significantly less likely than those with FD to report decreased appetite (16.3\% $v 28 \% ; \mathrm{p}=0.02)$. This translated to a crude odds ratio of 0.49 (95\% CI 0.26-0.91); $p=0.02$ ) for a diagnosis of upper gastrointestinal disease among those who reported decreased appetite (see table 5; unadjusted models).

\section{Non-alarm features}

Three pain based items discriminated upper organic disease from FD in univariate tests (see table 2). Compared with patients with FD, those with organic disease were significantly less likely to report upper abdominal pain $(66.1 \% v$ $88.6 \% ; \mathrm{p}<0.001$ ), pain on more than six occasions in the previous year $(64.5 \% \vee 82.9 \%$; $\mathrm{p}=0.004)$, and pain that radiated outside of the abdomen $(27.5 \% \vee 40.0 \% ; \mathrm{p}=0.04)$. Patients with upper gastrointestinal disease were also less likely to report constipation $(3.2 \% v 10.0 \% ; \mathrm{p}=0.02)$ but were significantly more likely to report heartburn $(55.0 \%$ v $41.4 \%$; $\mathrm{p}=0.05)$. Aspirin use was significantly more common among patients with organic disease $(33.1 \% \vee 11.4 \% ; \mathrm{p}<0.001)$ and paracetamol use was more common among those with FD (78.6\% v 66.1\%; $\mathrm{p}<0.0001)$.

Logistic regression identified five non-alarm feature items that were significantly related to a diagnosis of upper gastrointestinal disease (see table 5: unadjusted models). The odds of a diagnosis of organic disease were significantly lower among patients who reported upper abdominal pain (OR 0.27 (95\% CI $0.12-0.60) ; p=0.002$ ), constipation (OR 0.28 (95\% CI 0.09-0.89); $\mathrm{p}=0.03$ ), and paracetamol use (OR 0.47 (95\% CI $0.24-0.92) ; p=0.03$ ). In contrast, the odds of a diagnosis of organic disease were higher among patients reporting heartburn (OR 2.12 (95\% CI 1.19-3.79); $\mathrm{p}=0.01$ ) and aspirin use (OR 3.84 (95\% CI 1.68-8.75); $\mathrm{p}=0.001$ ).

\section{Alarm features: adjusted model}

Following adjustment for the significant (non-alarm) predictors, decreased appetite was no longer a significant predictor (OR 0.56 (95\% CI 0.29-1.10); $\mathrm{p}=0.09$; see table 5, adjusted model). However, comparisons of the model statistics indicated that case classification was better when this alarm feature was retained (table 6). The model containing non-alarm feature items alone correctly classified only $8.6 \%$ of patients with a diagnosis of FD. This improved to $17.1 \%$ for the model which included decreased appetite and the non-alarm features. Both models correctly classified patients with organic disease in $99 \%$ of cases.

\begin{tabular}{|c|c|c|c|}
\hline & \multicolumn{2}{|c|}{ Predicted } & \multirow[b]{2}{*}{$\%$ correct } \\
\hline & IBS & Organic & \\
\hline \multicolumn{4}{|c|}{ Model 1. Alarm features only } \\
\hline IBS & 198 & 16 & 92.5 \\
\hline Organic disease & 45 & 21 & 31.8 \\
\hline \multirow{2}{*}{\multicolumn{4}{|c|}{ Model 2. Other symptoms and risk factors only (non-alarm features) }} \\
\hline \multicolumn{2}{|c|}{ Observed } & & \\
\hline IBS & 204 & 10 & 95.3 \\
\hline Organic disease & 42 & 24 & 36.4 \\
\hline \multicolumn{4}{|c|}{ Model 3. Alarm features adjusted for non-alarm features } \\
\hline \multicolumn{4}{|c|}{ Observed } \\
\hline IBS & 205 & 9 & 95.8 \\
\hline Organic disease & 32 & 34 & 51.5 \\
\hline \multicolumn{4}{|c|}{ Model 4. Model 3 adjusted for Manning criteria (2+ symptoms) } \\
\hline \multicolumn{4}{|c|}{ Observed } \\
\hline IBS & 203 & 11 & 94.9 \\
\hline Organic disease & 34 & 32 & 48.5 \\
\hline \multicolumn{4}{|c|}{ Model 5. Model 3 adjusted for Manning criteria ( $3+$ symptoms) } \\
\hline \multicolumn{4}{|c|}{ Observed } \\
\hline IBS & 206 & 8 & 96.3 \\
\hline Organic disease & 32 & 34 & 51.5 \\
\hline \multicolumn{4}{|c|}{ Model 6. Model 3 adjusted for Manning criteria (4+ symptoms) } \\
\hline \multicolumn{4}{|c|}{ Observed } \\
\hline IBS & 206 & 8 & 96.3 \\
\hline Organic disease & 31 & 35 & 53.0 \\
\hline
\end{tabular}

IBS, irritable bowel syndrome. 
Table 5 Multivariate relationships between alarm symptoms and upper gastrointestinal diagnostic groups: unadjusted and adjusted effects

\begin{tabular}{|c|c|c|c|c|c|c|}
\hline & \multicolumn{3}{|c|}{ Unadjusted models } & \multicolumn{3}{|c|}{ Adjusted model* } \\
\hline & OR & $95 \% \mathrm{Cl}$ & $\mathrm{p}$ Value & $\overline{\mathrm{OR}}$ & $95 \% \mathrm{Cl}$ & p Value \\
\hline \multicolumn{7}{|l|}{ Alarm features } \\
\hline Decreased appetite & 0.49 & $0.26-0.91$ & 0.023 & 0.56 & $0.29-1.10$ & 0.09 \\
\hline \multicolumn{7}{|c|}{ Other symptoms and risk factors } \\
\hline Upper abdominal pain & 0.27 & $0.12-0.60$ & 0.002 & 0.29 & $0.13-0.65$ & 0.003 \\
\hline Constipation & 0.28 & $0.09-0.89$ & 0.030 & 0.30 & $0.10-0.97$ & 0.044 \\
\hline Heartburn & 2.12 & $1.19-3.79$ & 0.011 & 2.17 & $1.21-3.90$ & 0.009 \\
\hline Any aspirin use & 3.84 & $1.68-8.75$ & 0.001 & 3.92 & $1.72-8.96$ & 0.001 \\
\hline Any paracetamol use & 0.47 & $0.24-0.92$ & 0.028 & 0.46 & $0.24-0.91$ & 0.024 \\
\hline
\end{tabular}

*Adjustments were performed for significant alarm features and non-alarm features, respectively.

$\mathrm{OR}$, odds ratio; $95 \% \mathrm{Cl}, 95 \%$ confidence interval.

\section{DISCUSSION}

The presence of alarm features in patients with symptoms suggestive of IBS should shift the physician's differential diagnosis towards structural or inflammatory conditions based on the present results. However, the present data demonstrate that the actual diagnostic yield of most of the alarm features assessed is limited when the Manning criteria are taken as the basis of the diagnosis. While in IBS certain alarm features, including age, sex, signs of rectal blood loss, and severe pain, had some value in discriminating IBS from lower gastrointestinal organic disease, alarm features were of little help in discriminating FD from upper gastrointestinal organic disorders. Although only four of the evaluated alarm features were significant discriminators of functional from organic lower gastrointestinal diseases, our results suggest that a symptom based diagnosis, combined with a limited amount of alarm feature data, improve the diagnostic yield of the history, as captured by a questionnaire.

Our data also suggest however that alarm features are the most important factors for a diagnosis of IBS. In the absence of alarm features, IBS was correctly identified in $93 \%$ of cases. When non-alarm features and Manning criteria were added, the diagnostic accuracy only increased slightly to $96 \%$.

The development of criteria to positively diagnose functional bowel disorders has evolved since the Manning criteria were first described. ${ }^{8}$ Kruis et al developed a different scoring system that included key gastrointestinal symptoms but also incorporated the results from a physical examination and basic laboratory tests. ${ }^{9}$ As both the Manning criteria and the Kruis scoring system have shown unsatisfactory sensitivity and the Kruis scoring system has proved to be too cumbersome for clinical practice, ${ }^{23}$ there have been a number of adaptations, with the Rome symptom based criteria being the most recent and widely accepted. The Rome II criteria primarily incorporate three of the Manning criteria although both diarrhoea and constipation are coded..$^{510}$ In a study by Vanner et al of the Rome I criteria, they found a sensitivity of only $35 \%$ in diagnosing IBS. $^{20}$ However, when alarm symptoms were included in the diagnostic workup, sensitivity increased to $63 \%$ with a specificity of $100 \% .{ }^{20}$ In a prospective arm of the same study, the Rome I criteria in combination with alarm symptoms had a positive predictive value of $98 \%$ in diagnosing IBS. In our study, the presence of three or four Manning criteria in combination with alarm symptoms similarly had a very high predictive value of diagnosing IBS (96\%), although the predictive value for diagnosing organic disease was poor, in part reflecting the heterogeneity of this category.

The present study had some limitations. There may have been less organic diseases in the sample and less cancers than would have been ideal for analysis. Few patients for example were found to have cancer, reflecting referral selection forces. Slightly more than $50 \%$ of patients had a diagnosis of organic disease while the rest had a functional bowel disorder. However, most patients with organic disease had symptoms that were judged to be most likely explained by the underlying condition. Another potential limitation of the present study is that we did not evaluate all possible alarm features but only those included on a validated questionnaire; the value of these other alarm symptoms cannot be determined here. Confirmation of the results we obtained with the IBS group model will require another study with a larger group of IBS patients. We considered undertaking a split half analysis to assess the reliability of our model and

\begin{tabular}{|c|c|c|c|}
\hline & \multicolumn{2}{|c|}{ Predicted } & \multirow[b]{2}{*}{$\%$ correct } \\
\hline & FD & $\begin{array}{l}\text { Organic } \\
\text { dyspepsia }\end{array}$ & \\
\hline \multicolumn{4}{|c|}{ Model 1. Alarm features only } \\
\hline \multicolumn{4}{|c|}{ Observed } \\
\hline Dyspepsia & 0 & 70 & 0.0 \\
\hline Organic disease & 0 & 250 & 100.0 \\
\hline \multicolumn{4}{|c|}{ Model 3. Other symptoms and risk factors only } \\
\hline \multicolumn{4}{|c|}{ Observed } \\
\hline Dyspepsia & 6 & 64 & 8.6 \\
\hline Organic disease & 1 & 249 & 99.6 \\
\hline \multicolumn{4}{|c|}{$\begin{array}{l}\text { Model 2. Alarm features adjusted for other symptoms and risk } \\
\text { factors }\end{array}$} \\
\hline \multicolumn{4}{|c|}{ Observed } \\
\hline Dyspepsia & 12 & 58 & 17.1 \\
\hline Organic disease & 3 & 247 & 98.8 \\
\hline
\end{tabular}


results. However, when using a split half method, a sufficient number of samples are needed and the groups in our study were not of adequate size for such an analysis.

A previous study evaluated whether extensive diagnostic testing might improve the diagnostic yield in IBS. $^{24}$ Laboratory tests, including erythrocyte sedimentation rate as well as stool tests for microorganisms, provided no increased diagnostic yield in the study. The authors concluded that these diagnostic tests should not be part of the routine evaluation for IBS unless there is a specific clinical indication from the history or physical examination. Although we did not assess the value of laboratory tests in the diagnostic workup of functional bowel disorders, our results show that history taking alone has a high positive predictive value, and suggest that laboratory tests will not add much to the diagnosis of IBS. Newer tests to document colonic inflammation may be useful; Tibble et al recently showed that faecal calprotectin was of value in the differential diagnosis of functional versus organic gastrointestinal disorders in a tertiary referral centre ${ }^{25}$ although the authors did not include alarm features in their evaluation of intestinal disease.

In patients presenting with dyspepsia, recent data have suggested that the presence of alarm features may increase the probability of identifying peptic ulcer disease or cancer. ${ }^{26}$ While only a minority of gastric cancers develop before the age of 55 years in Western countries, alarm features are present in $96 \%$ of these younger cases. ${ }^{27}$ However, when cancer presents with alarm features, the disease is advanced and usually incurable. ${ }^{28}$ In primary care, approximately $12 \%$ of patients with dyspepsia present with alarm features and most do not have cancer. ${ }^{29}$ On the other hand, the majority of patients who develop cancer or peptic ulceration do not present with alarm features at the initial consultation in primary care. ${ }^{30}{ }^{31}$ Indeed, the presence of alarm features in dyspeptic patients was associated with a low positive predictive value and a high negative predictive value in one study. ${ }^{30}$ Our data reflect a secondary care setting, and demonstrated that a symptom based diagnosis had a very poor positive predictive value for FD. Even in the most favourable model, only $17 \%$ of patients with FD could be correctly classified based on symptoms. Our study thus supports other data from a multicentre database ${ }^{32}$ and a secondary referral centre ${ }^{33}$ that evaluation of alarm features fails to satisfactorily improve the diagnostic yield of symptoms in FD.

In conclusion, the Rome criteria have standardised the field of functional gastrointestinal disorders and promoted new clinical and epidemiological research. Our results, as well as those of Vanner and colleagues, ${ }^{21}$ allow us to conclude that the Rome criteria and Manning criteria identify fewer patients as having IBS than are diagnosed by clinicians, suggesting a need to adjust the current diagnostic guidelines. However, we suggest that the Rome criteria for IBS should be expanded to include key alarm features. In contrast, the symptom criteria for FD should be modified to include specific alarm features, and unfortunately this condition still remains a diagnosis of exclusion.

\section{ACKNOWLEDGEMENT}

Supported by research grants from the National Health and Medical Research Council of Australia to Dr Talley

\section{Authors' affiliations}

J Hammer, Universitätsklinik für Innere Medizin IV, Abteilung für Gastroenterologie und Hepatologie, Vienna, Austria

G D Eslick, Department of Medicine, University of Sydney, Nepean Hospital, Penrith, New South Wales, Australia
S C Howell, School of Public Health, The University of Sydney, NSW, Australia

E Altiparmak, Turkiye Yuksek Ihtisas Hospital, Ankara, Turkey

N J Talley, Mayo Clinic, C.E.N.T.E.R., Rochester, MN, USA

\section{REFERENCES}

1 Talley NJ, Spiller R. Irritable bowel syndrome: a little understood organic bowel disease? Lancet 2002;360:555-64.

2 Longstreth GF. Irritable bowel syndrome: A multibillion-dollar problem. Gastroenterology 1995;109:2029-42.

3 Talley NJ, Gabriel SE, Harmsen WS, et al. Medical costs in community subjects with irritable bowel syndrome. Gastroenterology 1995; 109:1736-41.

4 Olden KW. Diagnosis of irritable bowel syndrome. Gastroenterology 2002;122:1701-14.

5 Thompson WG, Longstreth GF, Drossmann DA, et al. Functional bowel disorders and functional abdominal pain. Gut 1999;45(suppl II):॥43-7.

6 Talley NJ, Stanghellini V, Heading RC, et al. Functional gastrointestinal disorders. Gut 1999;45(suppl II):॥37-42.

7 Fass R, Longstreth G-F, Pimentel M, et al. Evidence- and consensus-based practice guidelines for the diagnosis of irritable bowel syndrome. Arch Intern Med 2001;161:2081-8.

8 Manning AP, Thompson WG, Heaton KW, et al. Towards positive diagnosis of the irritable bowel. BMJ 1978;2:653-4.

9 Kruis W, Thieme C, Weinzierl $M$, et al. A diagnostic score for the irritable bowel syndrome. Its value in the exclusion of organic disease. Gastroenterology 1984;87:1-7.

10 Thompson WG, Creed F, Drossman DA, et al. Functional bowel disorders and functional abdominal pain. Gastroenterol Int 1992;5:75-91.

11 Talley NJ, Phillips SF, Melton $\sqcup$, et al. Diagnostic value of the Manning criteria in irritable bowel syndrome. Gut 1990;31:77-81.

12 Poynard T, Couturier D, Frexinos J, et al. French experience of Manning's criteria in irritable bowel syndrome. Eur J Gastroenterol Hepatol 1992:4:747-52.

13 Jeong $\mathrm{H}$, Lee $\mathrm{HR}$, Yoo BC, et al. Manning criteria in irritable bowel syndrome: its diagnostic significance. Korean J Intern Med 1993;8:34-9.

14 Dogan UB, Unal S. Kruis scoring system and Mannings criteria in diagnosis of irritable bowel syndrome-ls it better to use combined? Acta Gastroenterol Belg 1996;59:225-8.

15 Thompson WG. Gastrointestinal symptoms in the irritable bowel compared with peptic ulcer and inflammatory bowel disease. Gut 1984;25:1089-92.

16 Frigerio G, Beretta A, Orsenigo G, et al. Irritable bowel syndrome: still far from a positive diagnosis. Dig Dis Sci 1992;37:164-7.

17 Hammer J, Talley NJ. Diagnostic criteria for the irritable bowel syndrome. Am J Med 1999; 107(suppl 1):5-11S

18 Bytzer P, Hansen JM, Schaffalitzky de Muckadell OB, et al. Predicting endoscopic diagnosis in the dyspeptic patient. The value of predictive score models. Scand J Gastroenterol 1997:32:118-25.

19 Patel RP, Petitta A, Fogel R, et al. The economic impact of irritable bowel syndrome in a managed care setting. J Clin Gastroenterol 2002;35:14-20.

20 Vanner SJ, Depew WT, Paterson WG, et al. Predictive value of the Rome criteria for diagnosing the irritable bowel syndrome. Am J Gastroenterol 1999:94:2912-17.

21 Talley NJ, Jones M. Self-reported rectal bleeding in a United States community: prevalence, risk factors, and health care seeking. Am J Gastroenterol 1998;93:2179-83.

22 Talley NJ, Phillips SF, Melton $\sqcup$ III, et al. A patient questionnaire to identify bowel disease. Ann Intern Med 1989;111:671-4.

23 Frigerio G, Beretta A, Orsenigo G, et al. Irritable bowel syndrome. Still far from a positive diagnosis. Dig Dis Sci 1992;37:164-7.

24 Tolliver BA, Herrera JL, DiPalma JA. Evaluation of patients who meet clinical criteria for irritable bowel syndrome. Am J Gastroenterol 1994;89:176-8.

25 Tibble JA, Sigthorsson G, Foster R, et al. Use of surrogate markers of inflammation and Rome criteria to distinguish organic from nonorganic intestinal disease. Gastroenterology 2002;123:450-60.

26 Voutilainen M, Mantynen T, Kunnamo I, et al. Impact of clinical symptoms and referral volume on endoscopy for detecting peptic ulcer and gastric neoplasms. Scand J Gastroenterol 2003;38:109-13.

27 Christie J, Shepherd NA, Codling BW, et al. Gastric cancer below the age of 55: implications for screening patients with uncomplicated dyspepsia. Gut 1997:41:513-17.

28 Gillen D, McColl KEL. Does concern about missing malignancy justify endoscopy in uncomplicated dyspepsia in patients aged less than 55 ? Am J Gastroenterol 1999;94:75-9.

29 Bodeger K, Eastwood PG, Manning SI, et al. Dyspepsia workload in urban general practice and implications of the British Society of Gastroenterology dyspepsia guidelines (1996). Aliment Pharmacol Ther 2000;14:413-20.

30 Meineche-Schmidt V, Jorgensen T. 'Alarm symptoms' in patients with dyspepsia: a three-year prospective study from general practice. Scand J Gastroenterol 2002;37:999-1007.

31 Canga C III, Vakil N. Upper GI malignancy, uncomplicated dyspepsia, and the age threshold for early endoscopy. Am J Gastroenterol 2002;97:600-3.

32 Wallace MB, Durkalski VL, Vaughan J, et al. Age and alarm symptoms do not predict endoscopic findings among patients with dyspepsia: a multicentre database study. Gut 2001;49:29-34.

33 Boldys $H$, Marek TA, Wanczura $P$, et al. Even young patients with no alarm symptoms should undergo endoscopy for earlier diagnosis of gastric cancer. Endoscopy 2003;35:61-7. 